\title{
Prediction of Muscle Strength Using Length and Width of the Bone
}

Tetsuo Maeda, PhD, RPT, AKIHIKo OOWATAshi, RPT, RyojI KiYAma, RPT, Yoshiniro Yoshida, PhD, MD, KiYohiro SAKaE, PhD, MD

Course of Physical Therapy, School of Health Sciences, Faculty of Medicine, Kagoshima University: 8-35-1 Sakuragaoka, Kagoshima 890-8506, Japan. TEL +81 99-275-6775

\begin{abstract}
Eighteen healthy women (mean \pm standard deviation, $20.6 \pm 0.9$ years old) were examined to determine the possibility of predicting muscle strength from the length and width of the bones. Estimating muscle strength by the variable reduction method of multiple regression analysis, a multiple correlation coefficient of $0.90(p<0.01)$ was obtained for grip strength in relation to three independent variables of height, distance between the medial and lateral epicondyle of the humerus, and distance between the medial malleolus of the tibia and lateral malleolus of the fibula. A multiple correlation coefficient of $0.84(p<0.01)$ was obtained for knee joint extension muscle strength in relation to three independent factors of distance between the medial and lateral epicondyle of the femur, distance between the medial malleolus of tibia and lateral malleolus of the fibula, and distance between the styloid process of the ulna and radius. Individual grip strength and the isometric knee extension muscle strength could be predicted from the length and width of bones in the present study.
\end{abstract}

Key words: Muscle strength, Prediction, Bone.

(This article was submitted Aug. 23, 2000, and was accepted Nov.20, 2000)

\section{INTRODUCTION}

Muscle strengths are critical factors and are determined for evaluation in physical therapy with a dynamometer and by the procedure of the manual muscle test. The results are often compared with those on the healthy contralateral side in unilaterally affected patients or with normal values that are derived from the examiner's subjective judgment. Individual normal muscle strengths may be predicted using multiple regression analysis of sex $^{1-4)}$, age ${ }^{1-6)}$, height ${ }^{1-5,7)}$, body weight ${ }^{1-5,7)}$, somatic fat rate ${ }^{1,2,7)}$, fat-free mass ${ }^{6)}$, circumference of $\operatorname{limbs}^{1,2,7)}$, and muscle cross-sectional areas ${ }^{7)}$ as the independent variables. However, because these values except for the height are changeable, they are not applicable to patients in the chronic stage.
Stable physical factors should be employed to predict standard muscle strength in patients with chronic disease. As stable factors in adults, the length and the width of the individual bones were considered in the present study. Although a significant correlation was recognized between bone sizes and muscle strength ${ }^{8,9)}$, there have not been any reports describing the relation of these factors to muscle strength prediction. Bone sizes in previous studies were determined with X-ray photography. We examined the relationship between muscle strength and the bone sizes measured from the surface of the skin.

This study investigated the possibility of predicting individual muscle strength from the length and the width of the bones. 


\section{SUBJECTS AND METHODS}

The length and the width of bones were measured in eighteen healthy women (mean \pm standard deviation; age, $20.6 \pm 0.9$ years old; height, $157.5 \pm$ $6.6 \mathrm{~cm}$; body weight, $54.2 \pm 5.7 \mathrm{~kg}$ ) with their consent.

The radial bone length and the spina-malleolar distance were measured as the length of bones with a tape measure. As the width of bones, the distance between the styloid processes of the ulna and radius (DUR), the distance between the medial and lateral epicondyle of the humerus (DMLH), the distance between the medial and lateral epicondyle of the femur (DMLF), the width of the patella (WP), and the distance between the medial malleolus of the tibia and lateral malleolus of the fibula (DTF) were measured by vernier caliper or vernier caliper with a pair of metallic boards $(16.1 \mathrm{~cm}$ long, $3.4 \mathrm{~cm}$ wide, $1 \mathrm{~mm}$ thick) attached at the measurement portion of the vernier caliper.

Repeat measurements were carried out on another day in order to examine the reproducibility of bone width measurements, because the bone width is not generally measured on the skin surface. The intraclass correlation coefficient (ICC 1.1) was calculated from the results ${ }^{10)}$.

Grip strength was measured twice with a Grip dynamometer(OG GIKEN Co., Okayama, Japan) in a standing position. The holding width of the Grip dynamometer was set as a half of the distance between the index finger tip and the inner part of the metacarpophalangeal joint of the thumb of the subjects. The isometric knee extension muscle strength was measured twice with KIN-COM 500H (Chattanooga Co., USA) in the sitting position at 90 degrees of knee joint flexion. The maximal value of two measurements was employed for analysis. Both measurements of the muscle strengths and the bone sizes were done on the left side.

Both the force (KEF) and the torque (KET) of knee extension muscle strength were determined for the statistical analysis. The correlation coefficient between each muscle strength of grip strength, KEF or KET, and the length, the width of bones, or height was calculated. Each muscle strength was estimated from the length and the width of bones and the height by the variable reduction method of multiple regression analysis. Significance was set at $\mathrm{p}<0.05$.

\section{RESULTS}

The result of the lengths and the widths of the bones and muscle strengths are shown in Table 1 . The correlation matrix of the muscle strengths to the lengths and the widths of bones are shown in Table 2. The height was considered as a length of the bone and was included as an analysis factor. A significant correlation was obtained for 6 of 8

Table 1. Physical characteristics of the subjects

\begin{tabular}{lrc}
\hline Variable & Mean & Standard deviation \\
\hline DUR (mm) & 47.4 & 2.59 \\
DMLH (mm) & 58.5 & 3.40 \\
Radius length $(\mathrm{cm})$ & 20.0 & 1.30 \\
DMLF (mm) & 96.5 & 4.00 \\
WP (mm) & 49.9 & 4.72 \\
DTF (mm) & 61.9 & 3.01 \\
Spina malleolar distance $(\mathrm{cm})$ & 79.8 & 4.07 \\
Grip strength $(\mathrm{kg})$ & 30.4 & 5.86 \\
KEF (N) & 494.6 & 96.36 \\
KET (Nm) & 148.0 & 33.69
\end{tabular}

DUR $=$ distance between the styloid procces of the ulna and radius. DMLH=distance between the medial and lateral epicondyle of the humerus. DMLF=distance between the medial and lateral epicondyle of the femur. $\mathrm{WP}=$ width of the patella. $\mathrm{DTF}=$ distance between the medial malleolus of the tibia and lateral malleolus of fibula. $\mathrm{KEF}=\mathrm{knee}$ joint extension force. $\mathrm{KET}=\mathrm{knee}$ joint extension torque.

Table 2. Correlation matrix of muscle strength to length and width of bones

\begin{tabular}{lccl}
\hline \multicolumn{2}{c}{ Independent variable } & \multicolumn{3}{c}{ Dependent variable } \\
\hline & Grip strength & KEF & KET \\
\cline { 2 - 4 } DUR & $0.60^{* *}$ & 0.35 & 0.46 \\
DMLH & $0.65^{* *}$ & 0.34 & $0.47^{*}$ \\
Radius length & $0.49^{*}$ & -0.04 & 0.27 \\
DMLF & 0.19 & $0.71^{* *}$ & $0.60^{* *}$ \\
WP & 0.29 & $0.54^{*}$ & $0.63^{* *}$ \\
DTF & $0.77^{* *}$ & 0.41 & $0.62^{* *}$ \\
Spina malleolar distance & $0.74^{* *}$ & 0.26 & $0.55^{*}$ \\
Height & $0.74^{* *}$ & 0.07 & 0.39
\end{tabular}

$* \mathrm{p}<0.05$. ** $\mathrm{p}<0.01$.

$\mathrm{KEF}=\mathrm{knee}$ joint extension force. $\mathrm{KET}=\mathrm{knee}$ joint extension torque. $\mathrm{DUR}=$ distance between the styloid procces of the ulna and radius. DMLH=distance between the medial and lateral epicondyle of the humerus. DMLF=distance between the medial and lateral epicondyle of the femur. $\mathrm{WP}=$ width of the patella. DTF=distance between the medial malleolus of the tibia and lateral malleolus of fibula. 
Table 3. Multiple regression analysis to predict muscle strength

\begin{tabular}{lccc}
\hline \multicolumn{1}{c}{ Equation } & Multiple R & Multiple R & $\mathrm{p}$ \\
\hline Grip strength $(\mathrm{kg})=0.36 \mathrm{height}(\mathrm{cm})+0.53 \mathrm{DMLH}(\mathrm{mm})+0.76 \mathrm{DTF}(\mathrm{mm})-105.18$ & 0.90 & 0.80 & 0.00003 \\
KEF $(\mathrm{N})=$ 20.1DMLF $(\mathrm{mm})+17.7 \mathrm{DTF}(\mathrm{mm})-16.4 \mathrm{DUR}(\mathrm{mm})-1765.5$ & 0.81 & 0.66 & 0.001 \\
KET $(\mathrm{Nm})=5.64 \mathrm{DMLF}(\mathrm{mm})+8.54 \mathrm{DTF}(\mathrm{mm})-5.04 \mathrm{DUR}(\mathrm{mm})-686.1$ & 0.84 & 0.70 & 0.0005
\end{tabular}

$\mathrm{DMLH}=$ distance between the medial and lateral epicondyle of the humerus. DTF=distance between the medial malleolus of the tibia and lateral malleolus of fibula. $\mathrm{EF}=\mathrm{knee}$ joint extension force. $\mathrm{DMLF}=$ distance between the medial and lateral epicondyle of the femur. DUR=distance between the styloid procces of the ulna and radius. KET=knee joint extension torque.

factors in relation to grip strength. There were also significant correlations for 2 of 8 factors in relation to $\mathrm{KEF}$, and 5 of 8 factors in relation to KET.

Three factors were selected from among the independent variables of 8 factors by the variable reduction method of multiple regression analysis, and the muscle strengths were estimated from these three factors. As a result, a multiple correlation coefficient (R) of 0.90 , and a coefficient of determination $\left(\mathrm{R}^{2}\right)$ of 0.80 , and $\mathrm{p}<0.00003$ were obtained for grip strength in relation to the independent variables of height, DMLH, and DTF. A multiple correlation coefficient $(\mathrm{R})$ of 0.81 , a coefficient of determination $\left(\mathrm{R}^{2}\right)$ of 0.66 and $p<0.001$ were obtained for KEF in relation to the independent variables of DMLF, DTF and DUR. A multiple correlation coefficient $(\mathrm{R})$ of 0.84 , a coefficient of determination $\left(\mathrm{R}^{2}\right)$ of 0.70 and $p<0.0005$ were obtained for KET in relation to the independent variables of DMLF, DTF and DUR (Table 3).

ICC $(1,1)$ of bone widths measured twice was calculated to examine reproducibility, and was within 0.81 to 0.92 . The lower limit of the $95 \%$ confidence interval for reproducibility was 0.56 , and the upper limit was 0.97 . The reproducibility of measurements of all bone widths was significant $(\mathrm{p}<0.05)$ (Table 4).

\section{DISCUSSION}

Individual grip strength and the isometric knee extension muscle strength could be predicted from the length and the width of bones in the present study.

The prediction accuracy in the present study indicated a multiple correlation coefficient of 0.81 to 0.90 , and a coefficient of determination of 0.66 to 0.80 . This prediction accuracy was similar to the values of other reports describing knee extension
Table 4. Intraclass correlation coefficients (ICC) of the bone width measurements

\begin{tabular}{lccc}
\hline Variable & ICC & \multicolumn{2}{c}{$95 \%$ confidence interval } \\
\hline & & Lower limit & Upper limit \\
\cline { 2 - 4 } DUR & 0.90 & 0.75 & 0.96 \\
DMLH & 0.85 & 0.64 & 0.94 \\
DMLF & 0.81 & 0.56 & 0.92 \\
WP & 0.89 & 0.73 & 0.96 \\
DTF & 0.92 & 0.79 & 0.97 \\
\hline
\end{tabular}

$\mathrm{DUR}=$ distance between the styloid proces of the ulna and radius. DMLH=distance between the medial and lateral epicondyle of the humerus. DMLF=distance between the medial and lateral epicondyle of the femur. $\mathrm{WP}=$ width of the patella. DTF=distance between the medial malleolus of the tibia and lateral malleolus of fibula.

muscle strength prediction (Table 5).

In previous reports demonstrating a large multiple correlation coefficient of muscle strength in relation to various factors, the range of subject ages was too great ${ }^{1,3,4,6)}$ and men and women were included in one group ${ }^{1,3,4)}$ (Table 5). In other reports obtaining a small multiple correlation coefficient, the range of subject ages was very narrow, and only men were examined ${ }^{5}$. When the range of muscle strength is great in the case of equal residuals, a high value was obtained for the multiple correlation coefficient. The greater the variation in muscle strength, the greater the errors in calculations using the equal multiple correlation coefficients. Therefore, the prediction accuracy should not be evaluated only by the value of the multiple correlation coefficient. In this study, because 19- to 22- year-old women were examined and their range of muscle strength was small, the muscle strength prediction may be more precise than that in previous reports $^{1,3-5)}$ (Table 5).

Since a vernier caliper was employed to measure the width of bones in the present study, ICC was 
Table 5. Comparison of the prediction accuracy of previous reports of knee extension muscle strength prediction

\begin{tabular}{|c|c|c|c|c|}
\hline Author & Independent variables & Subjects & Multiple R & Multiple $\mathrm{R}^{2}$ \\
\hline Neder, et al. ${ }^{4}$ & $\begin{array}{l}\text { sex, age, height, body weight, } \\
\text { physical activity index }\end{array}$ & $\begin{array}{l}20 \text { to } 80 \text {-year-old, men and women, } \\
96 \text { persons }\end{array}$ & 0.92 & 0.85 \\
\hline Gross, et al. ${ }^{1}$ & $\begin{array}{l}\text { sex, age, height, body weight, } \\
\text { somatic fat rate, thigh circumference }\end{array}$ & $\begin{array}{l}10 \text { to } 80 \text {-year-old, men and women, } \\
134 \text { persons }\end{array}$ & 0.87 & 0.76 \\
\hline Madsen, et al. ${ }^{6}$ & age, leg fat-free mass & $\begin{array}{l}18 \text { to } 87 \text {-year-old, women, } \\
100 \text { persons }\end{array}$ & 0.86 & 0.74 \\
\hline $\begin{array}{l}\text { NIMS Database } \\
\text { Consortium }^{\dagger}\end{array}$ & sex, age, height, body weight & $\begin{array}{l}18 \text { to } 80 \text {-year-old, men and women, } \\
493 \text { persons }\end{array}$ & 0.71 & 0.50 \\
\hline Balogun, et al. ${ }^{5}$ & age, height, body weight & $\begin{array}{l}18 \text { to } 28 \text {-year-old, men, } \\
64 \text { persons }\end{array}$ & 0.58 & 0.33 \\
\hline
\end{tabular}

† The National Isometric Muscle Strength Database Consortium ${ }^{3}$

used to examine the reproducibility of the measurements. The results of $\operatorname{ICC}(1,1) \mathrm{r}=0.81$ to $0.92, p<0.05$, were significant. This procedure using a measuring tape and vernier caliper is a small burden on the patient, and the physical therapist can easily utilize it in the clinical field.

Although in the present study the grip strength and isometric muscle strength of the knee extension were used as dependent variables, neither the isokinetic muscle strength nor the other muscle strengths were examined. It is necessary to examine the other muscle strengths and the isokinetic muscle strength as dependent variables in future. The subjects were women around 20 years old in the present study. Therefore, the results will not always be applicable to patients of other ages. Muscle strength decreases in parallel with age, and the results are not applicable to male patients. However, muscle strength prediction at the bed-side by this procedure will become feasible, if the study in this field is further extended in the future.

\section{CONCLUSION}

We examined the possibility of predicting individual muscle strength by the length and width of the bone in combination with the height. The grip strength and the isometric knee joint extension muscle strength were predictable with multiple correlation coefficients of 0.81 to 0.90 and coefficients of determination of 0.66 to 0.80 $(p<0.01)$ in the present study. It is thought that this procedure can be developed into a practical muscle strength prediction method.

\section{REFERENCES}

1) Gross MT, McGrain P, Demilio N, et al.: Relationship between multiple predictor variables and normal knee torque production. 1989, Phys Ther, 69: 54-62.

2) Gross MT, Credle JK, Hopkins LA, et al.: Validity of knee flexion and extension peak torque prediction models. 1990, Phys Ther, 70: 3-10.

3) The National Isometric Muscle Strength Database Consortium: Muscular weakness assessment: use of normal isometric strength data. 1996, Arch Phys Med Rehabil, 77: 1251-1255.

4) Neder JA, Nery LE, ShinZato GT, et al.: Reference values for concentric knee isokinetic strength and power in nonathletic men and women from 20 to 80 years old. 1999, J Orthop Sports Phys Ther, 29: 116126.

5) Balogun JA, Onigbinde AT: Predictors of the elbow flexors, knee extensors and knee flexors isometric strength in males, age 18-28: a preliminary report. 1991, J Phys Ther Sci, 3: 7-12.

6) Madsen OR, Lauridsen UB, Hartkopp A, et al.: Muscle strength and soft tissue composition as measured by dual energy x-ray absorptiometry in women aged 1887 years. 1997, Eur J Appl Physiol, 75: 239-245.

7) Mayhew JL, Piper FC, Ware JS: Anthropometric correlates with strength performance among resistance trained athletes. 1993, J Sports Med Phys Fitness, 33: 159-165.

8) Dequeker J, Van Tendeloo G: Metacarpal bone mass and upper-extremity strength in 18-year-old boys. 1982, Invest Radiol, 17: 427-429.

9) Plato $\mathrm{CC}$, Norris $\mathrm{AH}$ : Bone measurements of second metacarpal and grip strength. 1980, Human Biology, 52: 131-149.

10) Shrout PE, Fleiss JL: Intraclass correlations: uses in assessing rater reliability. 1979, Psychological Bulletin, 86: 420-428. 